\title{
On-chip Paper Electrophoresis for Ultrafast Screening of Infectious Diseases
}

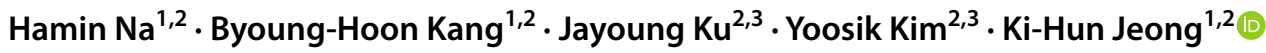

Received: 4 June 2021 / Revised: 20 July 2021 / Accepted: 2 August 2021 / Published online: 17 August 2021

(c) The Author(s) 2021

\begin{abstract}
The outbreak of new viral strains promotes advances in universal diagnostic techniques for detecting infectious diseases with unknown viral sequence. Long double-stranded RNA (dsRNA), a hallmark of infections, serves as a virus marker for prompt detection of viruses with unknown genomes. Here, we report on-chip paper electrophoresis for ultrafast screening of infectious diseases. Negatively charged RNAs pass through the micro and nanoscale pores of cellulose in order of size under an external electric field applied to the paper microfluidic channel. Quantitative separation of long dsRNA mimicking poly I:C was analyzed from 1.67 to $33 \mathrm{ng} \cdot \mu \mathrm{L}^{-1}$, which is close to the viral dsRNA concentration in infected cells. This paper-based capillary electrophoresis chip (paper CE chip) can provide a new diagnostic platform for ultrafast viral disease detection at the point-of-care (POC) level.
\end{abstract}

Keywords Infectious disease $\cdot$ Virus detection $\cdot$ Long dsRNA $\cdot$ Paper microfluidics $\cdot$ Point-of-care test

\section{Introduction}

Infectious disease diagnostics aims at rapid diagnosis and isolation of patients to prevent further propagation of virus and introduction of new, and mutant strains. Reverse transcription-polymerase chain reaction (RT-PCR) [1] and microarray hybridization [2] have become standard methods for virus detection due to their high sensitivity to a specific sequence in viral genome. However, a target nucleic sequence is required for complementary primer or probe design, thus limiting the immediate detection of novel and mutant viruses whose genomic sequence remain unknown [3].

Ki-Hun Jeong

kjeong@kaist.ac.kr

1 Department of Bio and Brain Engineering, Korea Advanced Institute of Science and Technology (KAIST), 291

Daehak-ro, Yuseong-gu, Daejeon 34141, Republic of Korea

2 KAIST Institute for Health Science and Technology (KIHST), Korea Advanced Institute of Science and Technology (KAIST), 291 Daehak-ro, Yuseong-gu, Daejeon 34141, Republic of Korea

3 Department of Chemical and Biomolecular Engineering, Korea Advanced Institute of Science and Technology (KAIST), 291 Daehak-ro, Yuseong-gu, Daejeon 34141, Republic of Korea
Long viral double-stranded RNA (dsRNA) has been recently reported as a universal biomarker for virus $[4,5]$. Viral dsRNA features a long length of about kilo base pairs $(\mathrm{kb})$ and a double helix structure unlike human RNA including long single-stranded RNA (ssRNA) and short dsRNA [5]. Long dsRNA is produced abundantly as an intermediate of viral replication in human cells $[6,7]$ infected by various viruses, including positive-stranded RNA viruses, DNA viruses, dsRNA viruses [8], single-stranded DNA (ssDNA) viruses and a few negative-stranded RNA viruses [9]. Such intrinsic features of long dsRNA rationalize the use of long dsRNA as the universal virus marker and encourage the development of detection methods $[10,11]$. The detection of long dsRNA often utilizes the immunofluorescence based on antibody that specifically recognizes dsRNAs more than $40 \mathrm{bp}$ in length $[5,8,12]$. However, antibody based identification still limits timely virus detection due to the time-consuming process, including antibody incubation and target recognition [13, 14]. In addition, false positive results occur when the antibody recognizes human innate dsRNAs longer than $40 \mathrm{bp}$ [15]. Separation of viral long dsRNA from human innate dsRNA should be performed primarily for absolute quantification of viral long dsRNA. As a result, the integration of separation prior to detection of viral dsRNA is very crucial for rapid, and precise diagnosis of the infectious disease. 
Separation of nucleic acids can provide information about the presence of genomic biomarker for disease diagnosis $[16,17]$. For instance, the size distribution of cell-free DNA (cfDNA) was employed to predict ICU mortality of patients [18] and long dsRNA from plant leaves was electrophoretically separated to confirm viral infection in plants [19]. Recently, the increasing demand for point-of-care (POC) diagnostics led to the development of on-chip separation due to significant advantages such as time saving procedure, less sample consumption, and high portability [20-23]. In particular, microchip electrophoresis (ME) allows high speed separation by scaling down conventional bulk electrophoresis to on-chip electrophoresis [24]. However, additional processes such as nanofabrication or gel casting are required to form a sieving matrix in typical glass or PDMS based chips $[25,26]$. Several advent of microfluidic paper-based analytical devices ( $\mu$ PADs) overcome complexity in fabrication [27-30]. The micro-/nanoscale cellulose pores inherent in paper allow high resolution separation of molecules without additional processes for the sieving matrix [31,32]. Electrophoretic separation of fluorescent molecules or small proteins has been studied using paper microfluidics [33, 34]. However, separation of nucleic acid using the $\mu$ PADs still remains an unsolved area due to the conformational complexity of nucleic acid.

Here, we report a paper-based capillary electrophoresis chip (paper CE chip) for ultrafast screening of infectious diseases by quantitative separation of viral dsRNA (Fig. 1a). Long and short dsRNAs are separated according to their size by an external high electric field confined within the wax-patterned paper microfluidic channel and the cellulose micro-/nanofiber matrixes. Force balance between electrophoresis and electroosmosis influences the electrophoretic movement of negatively charged RNAs (Fig. 1b). Long dsRNA $(\sim \mathrm{kb})$ is separated from RNA mixtures and quantitatively analyzed by the relationship between long dsRNA concentration and fluorescence intensity. This work reports the first approach for electrophoretic separation of RNA on a paper microfluidic device.

\section{Results and Discussion}

The whole operation from electrophoretic separation to RNA detection was performed with fully packaged paper-based CE device including the paper CE chip and a polylactic acid (PLA) housing (Fig. 2a). The paper CE chip is mounted on the rectangular groove of bottom plate and fixed by the anchor plate of PLA housing. The top cover of housing serves as a lid for reducing the sample evaporation from the paper microfluidic channel and provides injection ports for running buffer and Au electrodes. Two Au electrodes as anode and cathode are connected onto the injection ports of PLA housing to contact with the midpoints of buffer reservoirs on the paper CE chip. An external electric field is applied to the paper CE chip through the electrodes. The paper CE chip consists of two buffer reservoirs, a sample inlet, and a separation channel (Fig. 2b). The paper microfluidic channel was printed in wax on the cellulose paper. The wax printed paper was heated on a hotplate at $150{ }^{\circ} \mathrm{C}$ for $3 \mathrm{~min}$ so that the top wax layer penetrates the cellulose pores to form hydrophobic fluid barrier. The wax invades the (a)

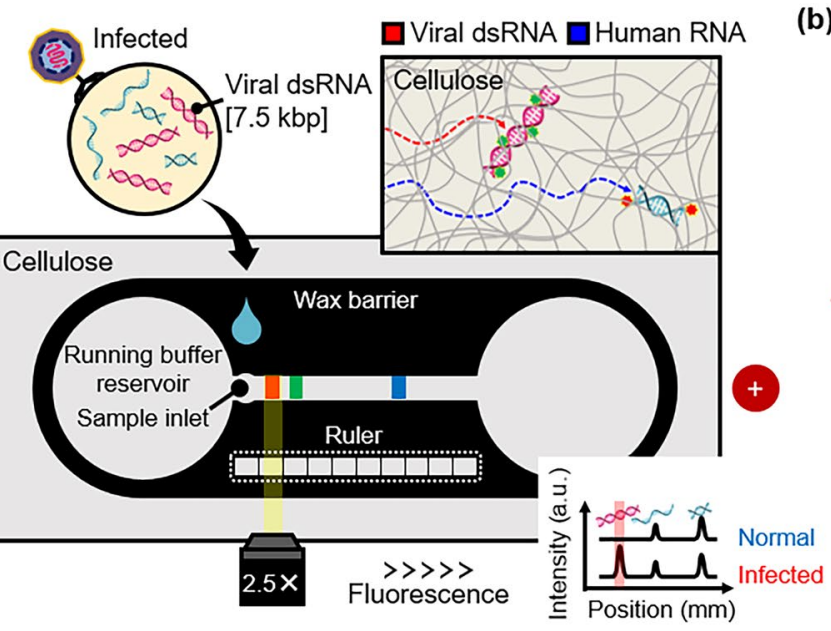

(b)

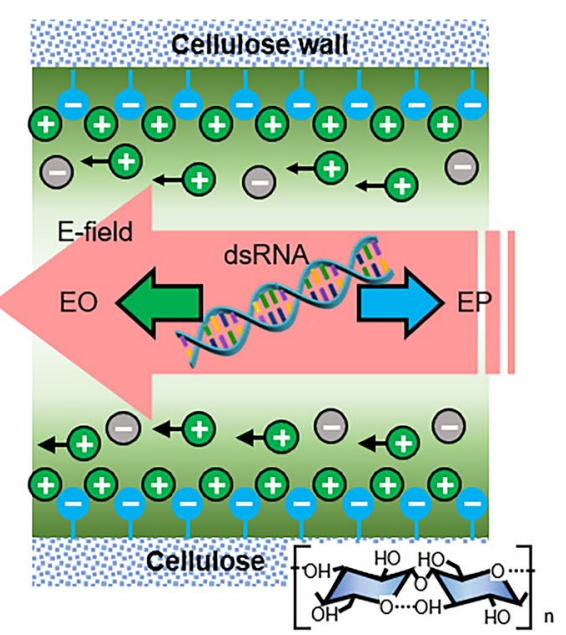

Fig. 1 Paper microfluidic chip for electrophoretic separation of viral long double-stranded RNAs (dsRNAs). a Schematic illustration of paper CE chip. The red band on the separation channel indicates the electrophoretic band of viral dsRNA, and the green and blue bands indicate the electrophoretic bands of various human RNAs. The small rectangles below the main channel serves as a ruler to locate electrophoretic bands roughly. b Force balance of electrophoresis (EP) and electroosmosis (EO). Electroosmotic flow (EOF) from anode to cathode interferes with the electrophoretic movement of RNA 
(a)

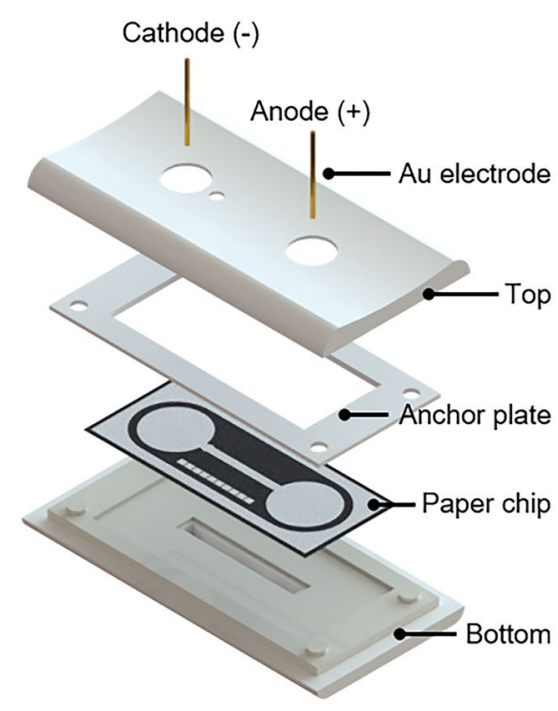

(b)
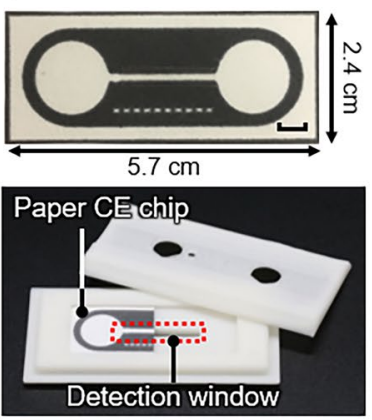

Detection window

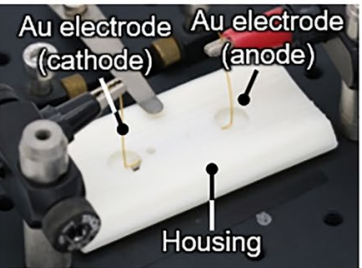

(c)
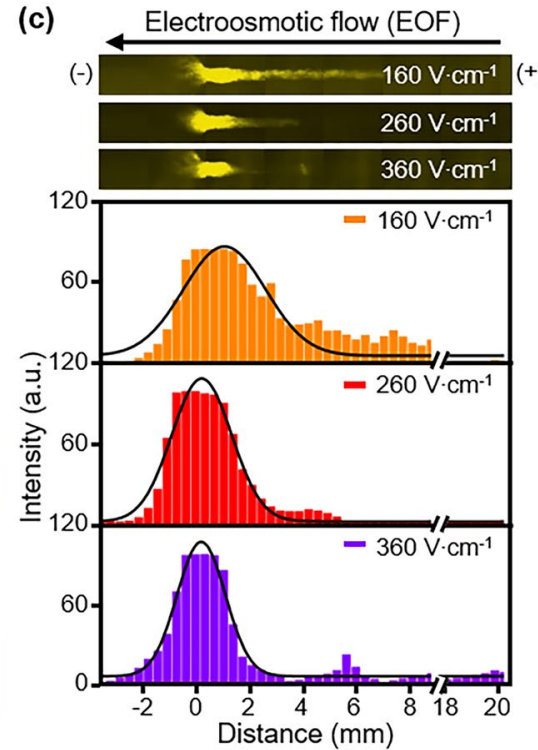

Fig. 2 a Fully packaged paper CE chip. An external electric field is applied through Au electrodes in the inlets at both ends. b Optical images of wax printed paper CE chip and polylactic acid (PLA) housing. Fluorescence signal of RNA is detected through the detec- tion window at the bottom. (Scale bar: $5 \mathrm{~mm}$ ) c Electroosmotic flow depending on applied electric field. Fluorescence images of rhodamine B (top) and fluorescence intensity profiles under each electric field (bottom) demonstrate that EOF increases with external E-field hydrophilic channel pattern during the melting process and results in reducing the channel width by about $1 \mathrm{~mm}$. Therefore, the initial channel width was determined to be $2 \mathrm{~mm}$ wide to prevent the blockage of flow path by hydrophobic wax. The final width was reduced to $1 \mathrm{~mm}$ as a result of wax invasion after heating. The channel length was determined on the basis of electrophoretic movement of fluorescein isothiocyanate (FITC), which is utilized as a reference for negatively charged small molecules with high electrophoretic mobility [33, 35]. The electrophoretic movement of FITC was measured by using electrophoretic separation of FITC and toluidine blue (TB) (Fig. S1). Positively charged TB and negatively charged FITC moved toward the cathode and the anode, respectively, depending on their charges after 5 min of paper CE at $210 \mathrm{~V} \cdot \mathrm{cm}^{-1}$. FITC is detected at the distance of $20 \mathrm{~mm}$ from the sample inlet, and the migration distance of FITC was set as the lower limit of the channel length. The channel lengths longer than $20 \mathrm{~mm}$ require higher voltages to generate the same electric field within $20 \mathrm{~mm}$ long channel. Therefore, the initial channel length was set to $20 \mathrm{~mm}$, which is the shortest length capable of electrophoresis of FITC.

On-chip paper electrophoresis consists of the procedures of buffer injection, electric field generation, and sample injection. Short RNAs move relatively faster than long RNAs due to the inverse relationship between the electrophoretic mobility and the molecular size [36]. Force balance between electrophoresis and electroosmosis governs the movement of RNA bands within the separation channel
[37]. Electroosmosis is the bulk solution movement that occurs in the opposite direction to electrophoresis when a strong electric field $\left(>100 \mathrm{~V} \cdot \mathrm{cm}^{-1}\right)$ interacts with the surplus of cations near the negatively charged cellulose surface [38]. The electric field dependence of electroosmosis was monitored with a neutral molecule of rhodamine $B(\mathrm{RhB})$ (Fig. 2c). RhB diffuses to the middle of the separation channel under a low electric field of $160 \mathrm{~V} \cdot \mathrm{cm}^{-1}$, but as the electric field increases, the diffusion of $\mathrm{RhB}$ is suppressed by the strong electroosmotic flow (EOF) from anode to cathode. The fluorescence intensity profile according to the migration distance confirms the RhB peak shifts toward the cathode with increasing electric field. The EOF-driven RhB movement occurs significantly under $360 \mathrm{~V} \cdot \mathrm{cm}^{-1}$, resulting in the peak shift and narrow fluorescent band of RhB.

The peak width serves an important role in evaluating the separation resolution during the electrophoresis. Electrophoretic movement of RNA depending on the electric field and the channel width were analyzed to optimize separation parameters for narrow peaks. Cy3-tagged 19mer ssRNA was targeted as a representative of typical RNA in human cells. Fluorescence emitted from Cy3 was quantified by converting the fluorescence images into the sum of the grayscale values of each pixel. The electrophoretic separation of Cy3tagged 19mer ssRNA was performed under a wide range of electric field from 160 to $360 \mathrm{~V} \cdot \mathrm{cm}^{-1}$ for $5 \mathrm{~min}$ using a $1.0 \mathrm{~mm}$ wide channel. A RNA band is not observed under $160 \mathrm{~V} \cdot \mathrm{cm}^{-1}$ because the low electric field generates a wide and ambiguous band across the whole channel due to the 
weak electrophoretic mobility and EOF. However, a clear RNA band is formed at a specific location within the separation channel under $260 \mathrm{~V} \cdot \mathrm{cm}^{-1}$. The RNA band mainly results from the optimal force balance between electrophoretic RNA movement and EOF. Above $260 \mathrm{~V} \cdot \mathrm{cm}^{-1}$, a wide band is formed at the front of the channel due to the strong EOF generation, which suppresses the electrophoretic movement of RNA. The full width at half maximum (FWHM) of the fitted curves in fluorescence intensity profile evaluates electrophoretic resolution at each electric field (Fig. 3a). The smallest FWHM at $260 \mathrm{~V} \cdot \mathrm{cm}^{-1}$ certifies the clearest band formation. Such a similar tendency is shown in the channel width-dependent electrophoretic movement of RNA. The $0.5 \mathrm{~mm}$ wide channel is so narrow that a large amount of RNA cannot pass through the channel and form a single specific band in the middle of the channel. RNAs migrate in one narrow band in the wider channels of the 1.0 and $1.5 \mathrm{~mm}$ with the smallest FWHM of $1.7 \mathrm{~mm}$ (Fig. 3b). Further increase in channel width results in peak broadening due to the diffusion of short ssRNA.

The separation efficiency was evaluated by a separation resolution (SR) metric, the distance between two peaks divided by the average peak width. The electric field and the channel width-dependent separation efficiency was analyzed with two different molecules, fluorescein-tagged poly I:C (1.5-8 kb) and Cy3-tagged 19 bp dsRNA. Long poly I:C hardly moves from the sample inlet, while 19 bp dsRNA moves toward anode along the channel. The SR increases with the electric field up to $235 \mathrm{~V} \cdot \mathrm{cm}^{-1}$ and decreases thereafter due to the significant band broadening of poly (a)

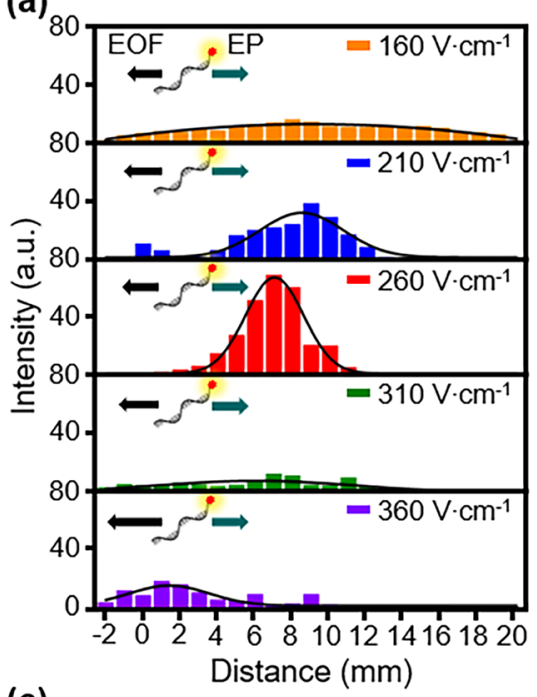

(c)

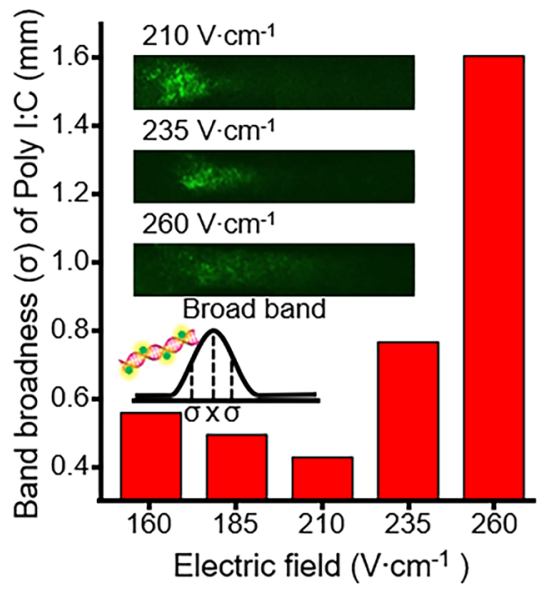

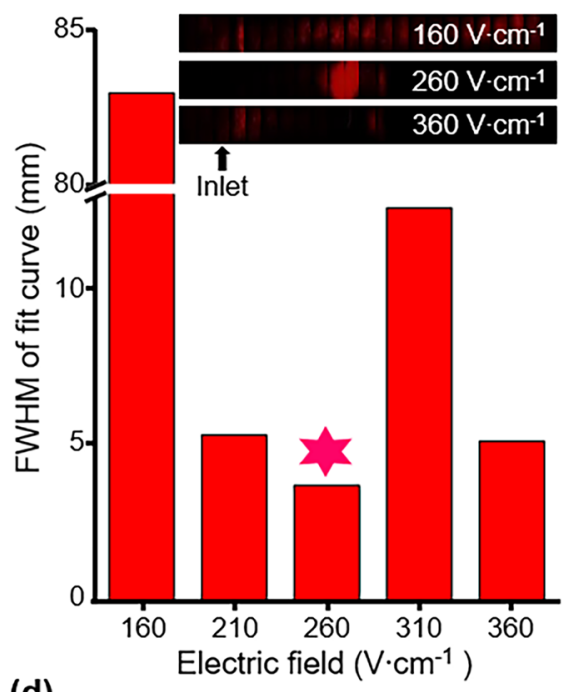

(d)

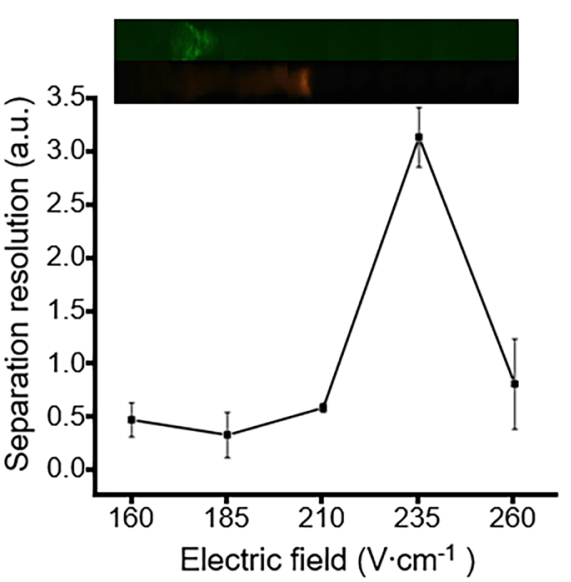

(b)

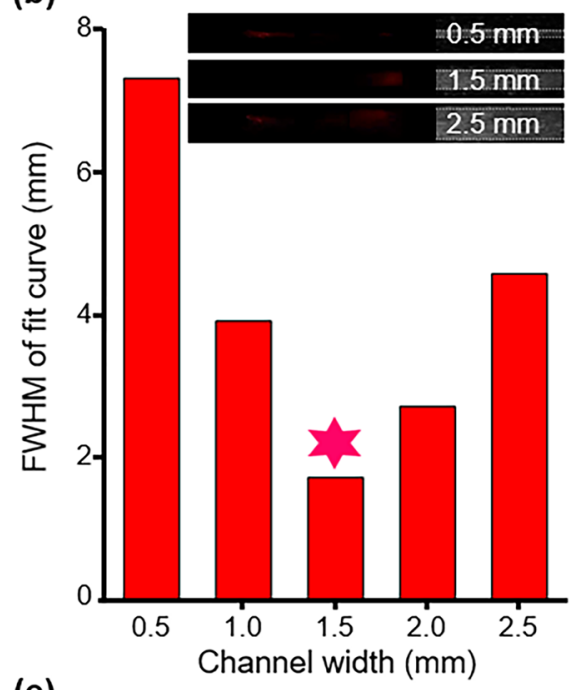

(e)

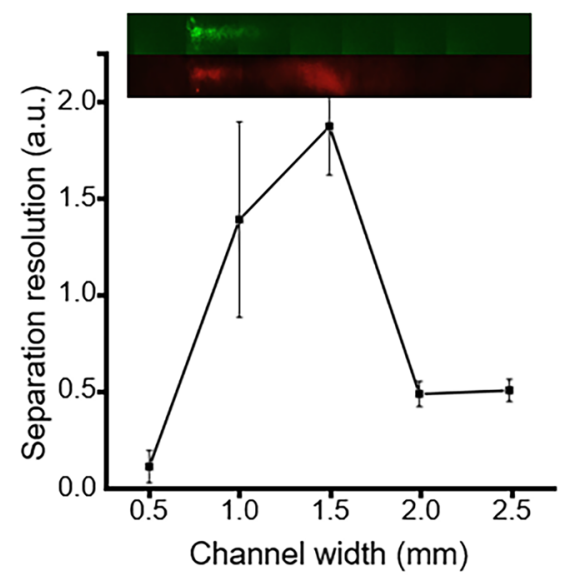

Fig. 3 Characterization of separation parameters. a Electric field dependent electrophoretic movement of Cy3-tagged 19mer ssRNA (left) and the FWHM of fit curve depending on electric field (right). The smallest FWHM at $260 \mathrm{~V} \mathrm{~cm}^{-1}$ is marked with a red star. b The FWHM of fit curve depending on channel width. The small- est FWHM at $1.5 \mathrm{~mm}$ is marked with a red star. c Band broadness of poly $\mathrm{I}: \mathrm{C}(1.5-8 \mathrm{~kb})$, i.e., mimicking viral long dsRNA, indicating the standard deviation $(\sigma)$ of poly I:C. Separation resolution (SR) depending on $\mathbf{d}$ E-field and e channel width 
I:C (Fig. 3c,d). The channel width-dependent separation has a good agreement with previously demonstrated the channel width-dependent electrophoretic movement. The SR increases with the channel width up to $1.5 \mathrm{~mm}$, resulting in a clear distinction between poly I:C and 19 bp dsRNA (Fig. 3e). The band broadening of 19 bp dsRNA becomes significant after $1.5 \mathrm{~mm}$ due to diffusion of $19 \mathrm{bp}$ dsRNA through cellulose pores.

Microfluidic separation using paper CE chip clearly demonstrates the inverse relationship between molecular size and electrophoretic mobility. The electrophoretic separation of a high diversity mixture including fluorescein-tagged poly I:C, Cy3-tagged 19 bp dsRNA, and FITC was achieved using the paper CE chip. FITC was chosen for modeling short nucleic acids or negatively charged small proteins in cell lysates. Relative sizes of poly I:C, 19 bp dsRNA, and FITC can be compared in mass unit (kDa), 2096.67, 13.26, and 0.39 kDa, respectively. The molecules were electrophoretically separated in order of poly I:C, 19 bp dsRNA, and FITC from the inlet by applying $210 \mathrm{~V} \cdot \mathrm{cm}^{-1}$ for $6 \mathrm{~min}$ on $1.5 \mathrm{~mm}$ wide cellulose channel (Fig. 4a). The band intensity in gel electrophoresis provides quantitative information of analytes [39]. Likewise, the quantification of poly I:C was achieved by the fluorescence intensity measurement near the sample inlet, where poly I:C is located after paper-based electrophoresis (Fig. 4b). The fluorescence images of $3600 \mu \mathrm{m} \times 3600 \mu \mathrm{m}$ rectangular area, including the sample inlet were acquired after paper-based electrophoresis of mixtures containing poly I:C concentrations varying from 0.33 to $33 \mathrm{ng} \cdot \mu \mathrm{L}^{-1}$. The fluorescence intensity increases with the poly I: $\mathrm{C}$ concentration from 1.67 to $33 \mathrm{ng} \cdot \mu \mathrm{L}^{-1}$. Note that $1.67 \mathrm{ng} \cdot \mu \mathrm{L}^{-1}$ is low enough to detect an infectious disease given that long dsRNAs of high concentration over $40 \mathrm{ng} \cdot \mu \mathrm{L}^{-1}$ are produced in an infected cell.

\section{Conclusion}

To be concluded, we have successfully demonstrated a paper CE chip for ultrafast screening of infectious diseases using viral long dsRNA as a universal biomarker. The micro-/ nanoscale cellulose pores allow size-based separation of RNA under strong electric fields within the wax printed microfluidic channel. A single and narrow electrophoretic peak of RNA was achieved by adjusting the separation parameters such as the electric field and the channel width. The parametric separation of RNA mixture further optimizes the separation parameters by the SR evaluation. Finally, the paper CE chip demonstrates the quantitative separation of poly I:C under optimized parameters. The paper CE chip can provide a new approach for rapid diagnosis of infectious diseases at the point-of-care (POC) level.

\section{Materials and Methods}

\subsection{Reagents and Materials}

Various synthetic RNAs were used as mimics for viral long dsRNA and human dsRNA. Fluorescein tagged polyinosinic:polycytidylic acid (poly I:C) $(1.5-8 \mathrm{~kb})$ was purchased from Invivogen. Cy3-tagged 19mer ssRNA [5'-UCGAAGUACUCAGCGUAAG-3'-(Cy3)] and 19 bp dsRNA [Forward: 5'-CUUACGCUGAGUACU UCGA-3'-(Cy3), Reverse: 5'-UCGAAGUACUCAGCG UAAG-3'-(Cy3)] were purchased from Bioneer. TBE $10 \mathrm{X}$ stock solution of running buffer was purchased from Sigma Aldrich. (a)

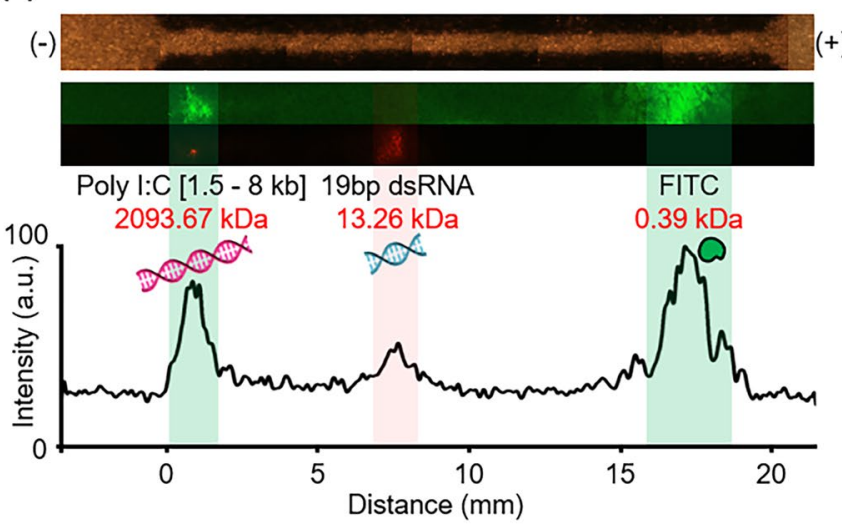

(b)

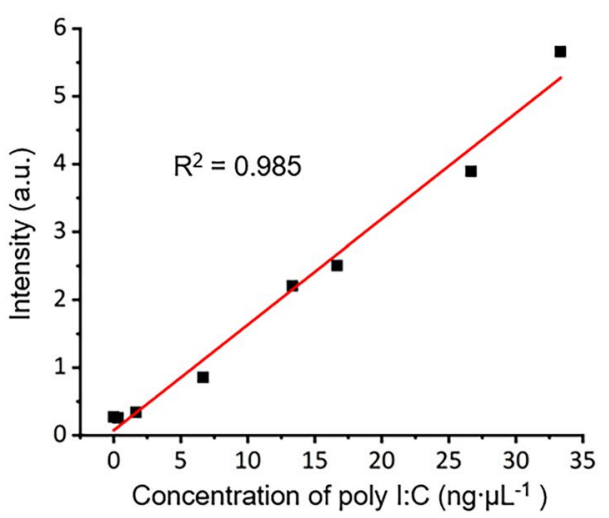

Fig. 4 Quantitative separation of poly I:C using the paper CE chip. a Electrophoretic separation of the mixture under optimized separation parameters. Relative molecular sizes are expressed in mass unit $(\mathrm{kDa})$. b Fluorescence intensity at the sample inlet depending on poly
I:C concentration in the mixture. Poly I:C was quantified from the 1.67 to $33.33 \mathrm{ng} \mu \mathrm{L}^{-1}$, which is close to viral dsRNA concentration in an infected cell 


\subsection{Fabrication of Paper CE System}

The paper CE chip consists of the two buffer reservoirs, a sample inlet, and a separation channel. The design of microfluidic channel was printed in wax on Whatman cellulose chromatography paper. The top layer of wax was heated for 3 min at $150{ }^{\circ} \mathrm{C}$ and formed a hydrophobic fluid barrier. A piece of water-impermeable adhesive tape was attached to the back of the paper CE chip to prevent fluid leakage through the cellulose pores. Fluid evaporation was minimized by attaching the optical adhesive tape on the separation channel. The paper CE chip housing was designed via SolidWorks 2017 and 3D printed with polylactic acid (PLA) filament. Each component was printed separately and assembled into a paper CE device. The physical dimension of fully packaged paper CE device is $8 \mathrm{~cm} \times 4 \mathrm{~cm} \times 8 \mathrm{~mm}$.

\subsection{Operation of Electrokinetic Motion in Paper CE Chip}

$20 \mu \mathrm{L}$ of TBE $5 \mathrm{X}$ running buffer (total $40 \mu \mathrm{L}$ ) was injected into each reservoir to fully wet the paper microfluidic channel. Electric field was applied for $5 \mathrm{~min}$ through $0.5 \mathrm{~mm}$ diameter Au wire by the high voltage AC-DC power supply (FJ1P120, Hanpower Co. Ltd.). The default values of electric field and channel width are $210 \mathrm{~V} \cdot \mathrm{cm}^{-1}$ and $1 \mathrm{~mm}$, respectively. $1 \mu \mathrm{L}$ of $47.9 \mathrm{ng} \cdot \mu \mathrm{L}^{-1}$ rhodamine $\mathrm{B}(\mathrm{RhB})$ was introduced into the sample inlet for electroosmotic flow (EOF) analysis. $2 \mu \mathrm{L}$ of 19mer ssRNA sample was used as the sample for electric field and channel width-dependent movement of RNA. Parameter-dependent separation was evaluated by calculating separation resolution between fluorescein tagged poly I:C and Cy3-tagged 19 bp dsRNA. $80 \mathrm{ng} \cdot \mu \mathrm{L}^{-1}$ of poly I:C and $2.47 \mathrm{ng} \cdot \mu \mathrm{L}^{-1}$ of $19 \mathrm{bp}$ dsRNA were mixed in equivalent proportion and $1 \mu \mathrm{L}$ of the mixture was injected into the sample inlet. Quantitative separation of poly $\mathrm{I}: \mathrm{C}$ was performed using mixtures consisting of $0.017 \mathrm{ng} \cdot \mu \mathrm{L}^{-1}$ of $19 \mathrm{bp}$ dsRNA, $3.23 \mathrm{ng} \cdot \mu \mathrm{L}^{-1}$ of FITC, and various concentrations of poly I:C from 1.67 to $33 \mathrm{ng} \cdot \mu \mathrm{L}^{-1}$. $210 \mathrm{~V} \cdot \mathrm{cm}^{-1}$ of electric field was applied for 6 min across $2 \mathrm{~cm} \times 1.5 \mathrm{~mm}$ separation channel.

\subsection{Fluorescence Image Acquirement for RNA Detection}

The fluorescence from RhB and fluorophores that attached to various RNAs were detected to locate the molecules after paper CE. An inverted confocal laser scanning microscope (Axiovert 200 M, Carl Zeiss Co. Ltd.) equipped with a CCD camera was used for fluorescence detection. The Cy3 attached to 19mer ssRNA and 19 bp dsRNA was excited by a mercury arc lamp combined with a 546/12 nm bandpass filter for transmission of excitation wavelengths.
Fluorescence images were acquired using a 575-640 nm bandpass filter as the emission filter. The optical section of $3000 \mu \mathrm{m} \times 4000 \mu \mathrm{m}$ on the CCD camera was captured along the channel. For RhB and fluorescein derivatives, a $543 \mathrm{~nm} \mathrm{He}-\mathrm{Ne}$ laser and a $488 \mathrm{~nm}$ Argon laser were used as excitation light sources. Laser scanned images were acquired by transmitted emission wavelengths from a $560 \mathrm{~nm}$ longpass filter for $\mathrm{RhB}$ and a $505 \mathrm{~nm}$ longpass filter for fluorescein derivatives. The optical section of $900 \mu \mathrm{m} \times 900 \mu \mathrm{m}$ was captured along the channel. Each image was converted to grayscale and divided into 10 along the row for the gradual change between adjacent images. The grayscale intensity change of each image was expressed as the fluorescence intensity profile according to the migration distance. The fluorescence intensity profile was fitted on the basis of Gaussian function for electrophoretic peak assignments.

Supplementary Information The online version contains supplementary material available at https://doi.org/10.1007/s13206-021-00034-z.

Acknowledgements This work was supported by grant No. MCM2021-N11210023 from KAIST Mobile Clinic Module Project, Ministry of Trade, Industry, and Energy (KMDF_PR_20200901_0074), and the National Research Foundation of Korea (NRF) grant funded by the Korea Government (MEST) (2021R1A2B5B03002428).

Open Access This article is licensed under a Creative Commons Attribution 4.0 International License, which permits use, sharing, adaptation, distribution and reproduction in any medium or format, as long as you give appropriate credit to the original author(s) and the source, provide a link to the Creative Commons licence, and indicate if changes were made. The images or other third party material in this article are included in the article's Creative Commons licence, unless indicated otherwise in a credit line to the material. If material is not included in the article's Creative Commons licence and your intended use is not permitted by statutory regulation or exceeds the permitted use, you will need to obtain permission directly from the copyright holder. To view a copy of this licence, visit http://creativecommons.org/licenses/by/4.0/.

\section{References}

1. Chan, J.F.W., et al. Improved molecular diagnosis of COVID-19 by the novel, highly sensitive and specific COVID-19-RdRp/Hel real-time reverse transcription-PCR assay validated in vitro and with clinical specimens. J. Clin. Microbiol. (2020). https://doi.org/ 10.1128/JCM.00310-20

2. Castro, A.C.H., et al. Preparation of genosensor for detection of specific DNA sequence of the hepatitis B virus. Appl. Surf. Sci. 314, 273-279 (2014)

3. Kim, D., et al. The architecture of SARS-CoV-2 transcriptome. Cell 181, 914-921.e10 (2020)

4. Monsion, B., et al. Efficient detection of long dsRNA in vitro and in vivo using the dsRNA binding domain from FHV B2 protein. Front. Plant Sci. 9, 70 (2018)

5. $\mathrm{Ku}, \mathrm{J}$., et al. Reactive polymer targeting dsRNA as universal virus detection platform with enhanced sensitivity. Biomacromol (2020). https://doi.org/10.1021/acs.biomac.0c00379 
6. Morris, T.J., Dodds, J.A. Isolation and analysis of double-stranded RNA from virus-infected plant and fungal tissue. Phytopathology 69, 854-858 (1979)

7. Kawai, T., Akira, S. Innate immune recognition of viral infection. Nat. Immunol. 7, 131-137 (2006)

8. Weber, F., Wagner, V., Rasmussen, S.B., Hartmann, R., Paludan, S.R. Double-stranded RNA is produced by positive-strand RNA viruses and DNA viruses but not in detectable amounts by negative-strand RNA viruses. J. Virol. 80, 5059-5064 (2006)

9. Son, K.-N., Liang, Z., Lipton, H.L. Double-stranded RNA is detected by immunofluorescence analysis in RNA and DNA virus infections, including those by negative-stranded RNA viruses. J. Virol. 89, 9383-9392 (2015)

10. Fujita, M., Adachi, K., Nagasawa, M. Development of a homogeneous time-resolved fluorescence assay for detection of viral double-stranded RNA. Anal. Biochem. 566, 46-49 (2019)

11. Decker, C.J., et al. dsRNA-Seq: identification of viral infection by purifying and sequencing dsRNA. Viruses 11, 943 (2019)

12. Schonborn, J., et al. Monoclonal antibodies to double-stranded RNA as probes of RNA structure in crude nucleic acid extracts. Nucleic Acids Res. 19, 2993-3000 (1991)

13. Ten Have, R., et al. Development of a fast ELISA for quantifying polio D-antigen in in-process samples. Biologicals 40, 84-87 (2012)

14. Mateer, E., Paessler, S., Huang, C. Confocal imaging of doublestranded RNA and pattern recognition receptors in negative-sense RNA virus infection. J. Vis. Exp. JoVE. (2019). https://doi.org/ $10.3791 / 59095$

15. Sakamoto, S., et al. Enzyme-linked immunosorbent assay for the quantitative/qualitative analysis of plant secondary metabolites. J. Nat. Med. 72, 32-42 (2018)

16. Kye, H.G., Ahrberg, C.D., Park, B.S., Lee, J.M., Chung, B.G. Separation, purification, and detection of cfDNA in a microfluidic device. BioChip J. 14, 195-203 (2020)

17. Shi, J., Zhang, R., Li, J., Zhang, R. Size profile of cell-free DNA: a beacon guiding the practice and innovation of clinical testing. Theranostics 10, 4737 (2020)

18. Dwivedi, D.J., et al. Prognostic utility and characterization of cell-free DNA in patients with severe sepsis. Crit. Care 16, R151 (2012)

19. Kozlakidis, Z., et al. Molecular characterization of the largest mycoviral-like double-stranded RNAs associated with Amasya cherry disease, a disease of presumed fungal aetiology. J. Gen. Virol. 87, 3113-3117 (2006)

20. Dorfman, K.D., King, S.B., Olson, D.W., Thomas, J.D.P., Tree, D.R. Beyond gel electrophoresis: microfluidic separations, fluorescence burst analysis, and DNA stretching. Chem. Rev. 113, 2584 (2013)

21. Marie, R., Pedersen, J.N., Mir, K.U., Bilenberg, B., Kristensen, A. Concentrating and labeling genomic DNA in a nanofluidic array. Nanoscale 10, 1376-1382 (2018)

22. Lee, H., Jung, J., Han, S.-I., Han, K.-H. High-speed RNA microextraction technology using magnetic oligo-dT beads and lateral magnetophoresis. Lab Chip 10, 2764-2770 (2010)

23. Kim, H., Huh, H.J., Park, E., Chung, D.-R., Kang, M. Multiplex molecular point-of-care test for syndromic infectious diseases. Biochip J. (2021). https://doi.org/10.1007/s13206-021-00004-5
24. Breadmore, M.C. Capillary and microchip electrophoresis: challenging the common conceptions. J. Chromatogr. A 1221, 42-55 (2012)

25. Lo, R.C., Ugaz, V.M. Microchip DNA electrophoresis with automated whole-gel scanning detection. Lab Chip 8, 2135-2145 (2008)

26. Wu, Q., et al. A millisecond micro-RNA separation technique by a hybrid structure of nanopillars and nanoslits. Sci. Rep. 7, 1-7 (2017)

27. Kang, B.H., Park, M., Jeong, K.H. Colorimetric Schirmer strip for tear glucose detection. Biochip J. 11, 294-299 (2017)

28. Park, M., Kang, B.H., Jeong, K.H. Paper-based biochip assays and recent developments: a review. BioChip J. 12, 1-10 (2018)

29. Altundemir, S., Uguz, A.K., Ulgen, K. A review on wax printed microfluidic paper-based devices for international health. Biomicrofluidics (2017). https://doi.org/10.1063/1.4991504

30. Hyung, S., Karima, G., Shin, K., Kim, K.S., Hong, J.W. A simple paper-based $\alpha$-amylase separating system for potential application in biological sciences. BioChip J (2021). https://doi.org/10.1007/ s13206-021-00022-3

31. Jung, H., Park, M., Kang, M., Jeong, K.H. Silver nanoislands on cellulose fibers for chromatographic separation and ultrasensitive detection of small molecules. Light Sci (2016). https://doi.org/10. 1038/lsa.2016.9

32. Nanthasurasak, P., Cabot, J.M., See, H.H., Guijt, R.M., Breadmore, M.C. Electrophoretic separations on paper: past, present, and future-a review. Anal. Chim. Acta 985, 7-23 (2017)

33. Mettakoonpitak, J., Henry, C.S. Electrophoretic separations on parafilm-paper-based analytical devices. Sens. Actuators B Chem. 273, 1022-1028 (2018)

34. Luo, L., Li, X., Crooks, R.M. Low-voltage origami-paper-based electrophoretic device for rapid protein separation. Anal. Chem. 86, 12390-12397 (2014)

35. Gong, M.M., Nosrati, R., San Gabriel, M.C., Zini, A., Sinton, D. Direct DNA analysis with paper-based ion concentration polarization. J. Am. Chem. Soc. (2015). https://doi.org/10.1021/jacs. $5 \mathrm{~b} 08523$

36. Stalcup, A.M. Chiral separations by capillary electrophoresis. In: Chiral Analysis, pp. 241-275. Elsevier, Oxford (2006)

37. Sugimoto, M., et al. DNA motion induced by electrokinetic flow near an Au coated nanopore surface as voltage controlled gate. Nanotechnology 26, 65502 (2015)

38. Yan, C., Xue, Y., Wang, Y. Capillary electrochromatography. Capillary Electromigration Separation Methods, pp. 209-233. Elsevier, Oxford (2018)

39. Forwood, J.K., Jans, D.A. Quantitative analysis of DNA-protein interactions using double-labeled native gel electrophoresis and fluorescence-based imaging. Electrophoresis 27, 3166-3170 (2006)

Publisher's Note Springer Nature remains neutral with regard to jurisdictional claims in published maps and institutional affiliations. 